\title{
Managing Sustainability in Fruit Production
}

\author{
N. Taragola \\ Institute for Agricultural and Fisheries Research \\ Merelbeke \\ Belgium
}

S. van Passel and W. Zwiekhorst
Hasselt University
Diepenbeek
Belgium

Keywords: management, sustainability, fruit production, monitoring tool

\begin{abstract}
As fruit growers are faced with a growing need for sustainable development, it is important to integrate sustainability into their management processes. This research applies and evaluates a self-analysis tool for entrepreneurs called the 'sustainability scan'. The scan identifies 23 sustainability themes, divided according to the 3P-framework (People, Planet and Profit). In the scan, it is assumed that the management of these themes is at the core of sustainable entrepreneurship. The 'sustainability scan' generally relates to larger companies as it includes a range of themes and steps in the management cycle that are most relevant to large firms. The empirical research suggests that fewer factors are relevant for small fruit producers. In order to reduce the bureaucracy as far as possible, it is suggested that only the most relevant themes and steps in the management cycle be retained. Relevant themes in the 'people' domain are: (i) food safety, (ii) food and health, (iii) terms of employment, and (iv) working conditions. In the 'planet' domain, the following themes can be retained: (i) water, (ii) waste, (iii) energy, (iv) minerals, (v) nature and landscape, and (vi) plant protection products. The 'profit' component can be limited to the following themes: (i) external orientation, (ii) value added, and (iii) capacity to change. Likewise, the number of steps in the management cycle can be reduced to: (i) objectives (with implied vision based on stakeholder dialogue), (ii) measures, (iii) monitoring, (iv) performance, and (v) transparency.
\end{abstract}

\section{INTRODUCTION}

The term 'sustainability' has become widely known as a result of the Brundtland report, where it was defined as 'meeting the needs of today without compromising the ability of future generations to meet their needs' (WCED, 1987). Sustainability is commonly translated as being economically viable, environmental sound and socially acceptable. Put another way, sustainability depends on the 3 P's - People, Planet, Profit (Elkington, 1999). 'People' pertains to fair and beneficial business practices toward labour and the community and region in which a company conducts its business. 'Planet' refers to sustainable environmental practices, whereas 'Profit' is the economic value created by the organization after deducting all the cost of all inputs, including the cost of capital.

Fruit production faces a whole range of sustainability issues, spanning all the economic, environmental and social dimensions (Granatstein and Kupferman, 2006; Bertschinger et al., 2009). The economic issues include rising production costs (e.g., labour) with static or declining output prices, global competition, the increasing power of supermarket chains, etc. Environmental issues relate to the use of plant protection products, fertilizers, water and energy, biodiversity, etc. Social sustainability includes labour issues, health aspects, urbanization and land use changes, food security, etc.

In order to stimulate sustainable development, Boone and ten Pierick (2005) developed a self-analysis tool for entrepreneurs called the 'sustainability scan'. The scan is based on self-assessment and is developed for larger companies with at least 5 permanent employees. The 'sustainability scan' is potentially a useful tool for fruit producers. However, many fruit companies are only small scale producers. Thus, a scan developed for small sized companies would be desirable. The aim of the current research is to apply and evaluate the existing 'sustainability scan' to the suit smallholder fruit 
producers in Belgium. Based on the findings of the empirical research, proposals for adaptation of the scan can be formulated.

\section{MATERIAL AND METHOD}

A 'sustainability scan' has been developed by Boone and ten Pierick (2005) from a study of literature and existing sustainability measurement tools. The scan consists of 25 themes grouped into three components: 'People', 'Planet' and 'Profit' (Fig. 1). In the component 'People' the following social themes are distinguished: (i) animal welfare, (ii) food safety, (iii) genetic modification, (iv) food and health, (v) noise and odour nuisance and (vi) emancipation and human rights. Labour-related themes include: (i) the terms of employment and (ii) working conditions. The component 'Planet' consists of the themes (i) air, (ii) water, (iii) soil, (iv) waste, (v) energy, (vi) minerals, (vii) nature and landscape, (viii) plant protection products and (ix) raw materials, auxiliary materials and equipment. The component 'Profit' includes the following themes related to competitiveness: (i) external orientation, (ii) chain harmonisation, (iii) value added, and (iv) the capacity to change. Some themes related to business ethics are added: (i) governance, (ii) charity, (iii) stimulating the local economy, and (iv) competition, fair trade and corruption.

In the 'sustainability scan' it is assumed that the management of these themes is at the core of sustainable entrepreneurship. The management cycle consists of eight steps (Fig. 1). A basis is formed through 'stakeholder dialogue', so that a clear picture can be gained of the wishes of society. On the basis of this consultation and the entrepreneur's vision of the company's role in society, a sustainability vision is established. A 'Vision' is the desired future position of a company (Raynor, 1998). This vision is subsequently translated into the formulation of 'objectives', the taking of 'measures', the placing of 'accountability' in the organisation (delegation of responsibilities) and the 'monitoring' of progress. All these components jointly determine the company's sustainability 'performance'. It is very important that the organisation should be 'transparent' to the stakeholders in relation to all the sustainability activities, because that, in turn, is the basis for the 'stakeholder dialogue'.

The 'sustainability scan', represented by the 25 themes and 8 steps in the management cycle, clearly relates to larger businesses. One can hypothesize that not all of these themes will be relevant for fruit growers. In order to evaluate the 'sustainability scan' in fruit production, it was applied to 11 fruit companies in 2009, situated in the south of Limburg province in Belgium. The respondents were randomly selected from a list of addresses made available by the PCF-Royal Station of Gorsem, Sint-Truiden and Boerenbond (farmers' association). The cultivated area ranged from 3 to 150 hectares (mean: 37.5 ha; median: 20.0 ha), while the number of labour units ranged from 1 to 18 (mean: 3.5; median: 3.5). These labour units were mostly employed during the harvest period. The aim of the empirical work was to identify which themes appear most relevant to fruit producers, whether they are actively involved, how they view their management cycle and their involvement with sustainability themes at each stage of the business cycle.

\section{RESULTS AND DISCUSSION}

\section{Relevance and Active Involvement in the Themes of the 'Sustainability Scan'}

Most of the respondents were actively involved in sustainability themes related to certification audits such as 'the use of plant protection products, minerals, energy and water', 'waste' and 'food safety' (Table 1). Some business themes, such as 'value added', 'capacity to change', 'external orientation' and 'chain harmonization' were important, demonstrating that most respondents were aware of the need to anticipate change. A significantly lower score is assigned to 'competition, fair trade and corruption', 'stimulating the local economy', 'charity' and 'governance'. The low scores for these themes can probably be attributed to the small size and lack of power in most small fruit companies. A low score was also given to 'noise and odour nuisance', 'air' and 'soil', while 'animal welfare' and 'genetic modification' were not at all relevant. These low 
scores are logical, taking into account the type of production. Remarkable is the large gap between relevance and active involvement for 'emancipation and human rights' and 'working conditions'. Fruit growers may think that 'emancipation and human rights' are relevant in a general societal-sense, but may feel that there is little they can do in a business-sense. However, there may be cause for concern about the large gap obtained for 'working conditions', as one can assume that most of the fruit growers can influence the working conditions in their enterprise.

\section{Number of Steps in the Management Cycle for Each Relevant Theme}

Although the management cycle for each theme in the 'sustainability scan' consists of 8 steps, on average, less than 4 steps were taken into account by the respondents ('People': 3.5 - 'Planet': 3.6 - 'Profit': 3.3) (Table 1). Looking at the individual themes, some peaks are observed in the management cycles 'People' and 'Profit'. The best scoring themes are 'working conditions' (5.8), 'plant protection products' (5.8) and 'food safety' (4.7). It is not surprising that these are also the themes included in the certification audits for food safety. The lowest scores were obtained for: 'emancipation and human rights' (2.0), 'raw and auxiliary materials and equipment' (2.8), 'chain harmonisation' (2.8) and 'charity' (2.8). As stated above, the results show that small businesses have the feeling that there is little that they can do about 'emancipation and human rights' in a business sense, contrary to improving the 'terms of employment' (3.6) and the 'working conditions' (5.8). Likewise, small businesses are less likely to feel that they can become involved in 'chain management' because of their small scale and lack of power. Furthermore, the management of 'charity' does not seem to be important because of the small scale of their company.

\section{Themes and Respondents Actively Involved for Each Step in the Management Cycle}

The results show that most attention is given to the management processes 'taking measures' and 'providing performance' in the domains 'Planet' and 'Profit' (Table 2). This is not surprising given the strict focus on environmentally sound and certified fruit production in Belgium. Remarkable is that the strategic management processes 'stakeholder dialogue' and 'vision' are neglected by many fruit growers. More attention is paid to the step 'setting objectives'. In the 'sustainability scan', 'stakeholder dialogue' and 'vision' were measured by asking questions about the use of formal management instruments. Because of scale related factors, formal management instruments and explicit vision statements are seldom used in small businesses (De Lauwere et al., 2002). However, although formal management instruments are seldom used, objectives should be based on an implicit vision, based on stakeholder dialogue (Taragola et al., 2010). Furthermore, little attention is paid to 'delegating responsibilities', which is in line with previous findings (Taragola et al., 2004). After all, most employees are charged with executive tasks, especially during the harvest period. Only in some of the larger fruit companies is responsibility for the sustainability themes delegated to family members or, in limited cases, to employees. The theme 'transparency' was also ignored or overlooked by the majority of fruit growers, especially for the Profit domain. The highest value for 'transparency' was obtained for the Planet domain, which can be explained by the certification regulations.

\section{Evaluation and Suggestions for the Adaptation of the 'Sustainability Scan' to the Small Business Context of Fruit Production}

The theoretical framework of the 'sustainability scan' clearly relates to larger companies, as it includes a range of themes and steps in the management process that are mostly relevant to larger companies. This empirical research provides an indication that fewer factors are relevant for small fruit producers. In order to reduce the bureaucracy as much as possible, it is suggested that only the most relevant themes and steps in the management process be retained. As a result of this empirical work, a revised theoretical framework is proposed that is easier and less time consuming to administer (Fig. 2). 
Relevant themes retained in the 'People' domain are: (i) food safety, (ii) food and health, (iii) terms of employment, and (iv) working conditions. In the 'Planet' domain, each of the following themes can be retained: (i) waste, (ii) energy, (iii) minerals, (iv) nature and landscape, and (v) plant protection products. The component 'Profit' can be limited to the following themes related to competitiveness: (i) external orientation, (ii) value added and (iii) capacity to change.

Likewise, the management cycle depicted in Figure 1 seems much more relevant to larger businesses than to smaller businesses. Typically, small businesses will focus on objectives, measures, monitoring and performance. One can assume that the low scores obtained for 'stakeholder dialogue' and 'vision' were partly due to the evaluation method used in the 'sustainability scan'. Although formal management instruments are seldom used in the small business context, it is important that there is an implied vision behind the objectives, which is based on stakeholder dialogue. Consequently, in the revised theoretical framework, the three distinct management steps 'stakeholder dialogue', 'vision' and 'objectives' are integrated in one single step called 'objectives (with implied vision based on stakeholder dialogue)'. Delegating responsibilities is less relevant in small fruit companies because of scale-related factors, and this can be removed from the management cycle. Of course, it should be noted that this step will be relevant for large sized fruit companies. Furthermore, since transparency is a core element in sustainable and socially responsible production, it is suggested to retain 'transparency' as a distinct step in the management process. Consequently, the number of management steps in the revised theoretical framework can be reduced to the five most important steps: 'objectives' (with implied vision based on stakeholder dialogue), 'measures', 'monitoring', 'performance' and 'transparency'.

\section{CONCLUSION}

The current research shows that the 'sustainability scan' developed by Boone and ten Pierick (2005) is potentially a very useful tool that could be adapted for small fruit or other agricultural companies. The scan was developed for larger companies with at least 5 permanent employees, whereas many fruit companies employ much fewer people. Based on the research findings a revised theoretical framework is formulated that comprises the themes and management steps which are most relevant for small fruit growers. Application of this proposed framework will result in a sustainability scan which is much easier and less time consuming to administer.

As the 'sustainability scan' is based on self-assessment, it could be interesting to couple the scan to monitoring instruments such as MOTIFS (MOnitoring Tool for Integrated Farm Sustainability) (Meul et al., 2008). In this way, by using benchmark tools, possible perception problems of self-evaluation can be decreased. Finally, a combination of the 'sustainability scan' with best management practices and learning examples could actively stimulate and optimise sustainable management.

\section{Literature Cited}

Bertschinger, L., Bauer, R., Carlen, C. and Doruchowski, G. 2009. Sustainability of horticulture in Europe (Environmental, Social, Economic): examples from the preand the post-harvest food chain. Acta Hort. 817:187-194.

Boone, J.A. and Pierick, E. 2005. Sustainability scan agrosector: an instrument for selfanalysis by companies (Duurzaamheidsscan agrosector: een instrument voor zelfanalyse door bedrijven). Rapport 4.05.07, LEI, Den Haag.

De Lauwere, C., Verhaar, K. and Drost, H. 2002. Het mysterie van het ondernemerschap. (The mystery of entrepreneurship). IMAG-Report 2002-02.

Elkington, J. 1997. Cannibals with forks: the triple bottom line of $21^{\text {st }}$ century business. Capstone, Oxford.

Granatstein, D. and Kupferman, E. 2006. Sustainable horticulture in fruit production. Acta Hort. 767:295-308.

Meul, M., van Passel, S., Nevens, F., Dessein, J., Rogge, E., Mulier, A. and van 
Hauwermeiren, A. 2008. MOTIFS: a monitoring tool for integrated farm sustainability. Agronomy for Sustainable Development 28(2):321-332.

Taragola, N., Marchand, F., Dessein, J. and Lauwers, L. 2010. Developing indicators for sustainable entrepreneurship in Flemish agriculture. In: A. Kakouris (ed.), Proceedings of the $5^{\text {th }}$ European Conference on Innovation and Entrepreneurship, p.302-610.

Taragola, N., van Lierde, D. and van Huylenbroeck, G. 2004. Task allocation and human resource management at glasshouse holdings in Flanders. Acta Hort. 655:151-158.

WCED. 1987. Our common future. Report of the World Commission on Environment and Development. Oxford University Press, Oxford.

\section{Tables}

Table 1. Relevance (a), active involvement (b), difference (a)-(b) (\% of respondents) and number of steps undertaken in the management cycle for the different themes of the sustainability scan.

\begin{tabular}{|c|c|c|c|c|}
\hline Theme & $\begin{array}{c}\text { Relevant } \\
\text { (\%) } \\
\text { (a) }\end{array}$ & $\begin{array}{c}\text { Actively } \\
\text { involved } \\
(\%) \\
\text { (b) }\end{array}$ & $\begin{array}{c}\text { Difference } \\
(\%) \\
(\mathrm{a})-(\mathrm{b})\end{array}$ & $\begin{array}{l}\text { Number of } \\
\text { steps in } \\
\text { management } \\
\text { cycle }\end{array}$ \\
\hline People & & & & 3.5 \\
\hline Animal welfare & 0 & 0 & 0 & - \\
\hline Food safety & 100 & 100 & 0 & 4.7 \\
\hline Genetic modification & 0 & 9 & -9 & 1.0 \\
\hline Food and health & 64 & 64 & 0 & 3.1 \\
\hline Noise and odour nuisance & 36 & 36 & 0 & 4.0 \\
\hline Emancipation and human rights & 73 & 55 & 18 & 2.0 \\
\hline Terms of employment & 82 & 73 & 9 & 3.6 \\
\hline Working conditions & 64 & 45 & 18 & 5.8 \\
\hline Planet & & & & 3.6 \\
\hline Air & 18 & 9 & 9 & 2.0 \\
\hline Water & 100 & 100 & 0 & 3.9 \\
\hline Soil & 45 & 45 & 0 & 3.4 \\
\hline Waste & 91 & 91 & 0 & 3.9 \\
\hline Energy & 91 & 82 & 9 & 3.7 \\
\hline Minerals & 91 & 82 & 9 & 3.8 \\
\hline Nature and landscape & 91 & 91 & 0 & 3.8 \\
\hline Plant protection products & 100 & 100 & 0 & 5.8 \\
\hline $\begin{array}{l}\text { Raw materials, auxiliary materials } \\
\text { and equipment }\end{array}$ & 64 & 45 & 18 & 2.8 \\
\hline Profit & & & & 3.3 \\
\hline External orientation & 91 & 91 & 0 & 3.0 \\
\hline Chain harmonisation & 91 & 91 & 0 & 2.8 \\
\hline Value added & 100 & 91 & 9 & 3.5 \\
\hline Capacity to change & 100 & 91 & 9 & 3.4 \\
\hline Governance & 27 & 27 & 0 & 3.3 \\
\hline Charity & 64 & 55 & 9 & 2.8 \\
\hline Stimulating local economy & 45 & 45 & 0 & 3.4 \\
\hline Competition, fair trade, corruption & 55 & 36 & 18 & 3.8 \\
\hline
\end{tabular}


Table 2. Percentage of the relevant themes involved in each step of the management cycle for the domains People, Planet and Profit (left) and percentage of the respondents that have gone through a certain step for at least one theme of the domains People, Planet and Profit (right).

\begin{tabular}{|c|c|c|}
\hline Step & $\begin{array}{c}\text { Themes } \\
(\%)\end{array}$ & $\begin{array}{c}\text { Respondents } \\
(\%)\end{array}$ \\
\hline \multicolumn{3}{|c|}{ Stakeholder dialogue } \\
\hline People & 28 & 64 \\
\hline Planet & 18 & 64 \\
\hline Profit & 5 & 18 \\
\hline \multicolumn{3}{|l|}{ Vision } \\
\hline People & 18 & 45 \\
\hline Planet & 27 & 55 \\
\hline Profit & 0 & 0 \\
\hline \multicolumn{3}{|c|}{ Setting objectives } \\
\hline People & 59 & 91 \\
\hline Planet & 55 & 91 \\
\hline Profit & 57 & 91 \\
\hline \multicolumn{3}{|c|}{ Taking measures } \\
\hline People & 63 & 91 \\
\hline Planet & 83 & 100 \\
\hline Profit & 79 & 100 \\
\hline \multicolumn{3}{|c|}{ Accountability delegating responsiblities } \\
\hline People & 11 & 9 \\
\hline Planet & 7 & 18 \\
\hline Profit & 24 & 27 \\
\hline \multicolumn{3}{|l|}{ Monitoring } \\
\hline People & 57 & 91 \\
\hline Planet & 57 & 100 \\
\hline Profit & 52 & 100 \\
\hline \multicolumn{3}{|c|}{ Providing performance } \\
\hline People & 65 & 91 \\
\hline Planet & 84 & 100 \\
\hline Profit & 73 & 100 \\
\hline \multicolumn{3}{|c|}{ Transparency } \\
\hline People & 15 & 45 \\
\hline Planet & 36 & 73 \\
\hline Profit & 2 & 9 \\
\hline
\end{tabular}




\section{Figures}

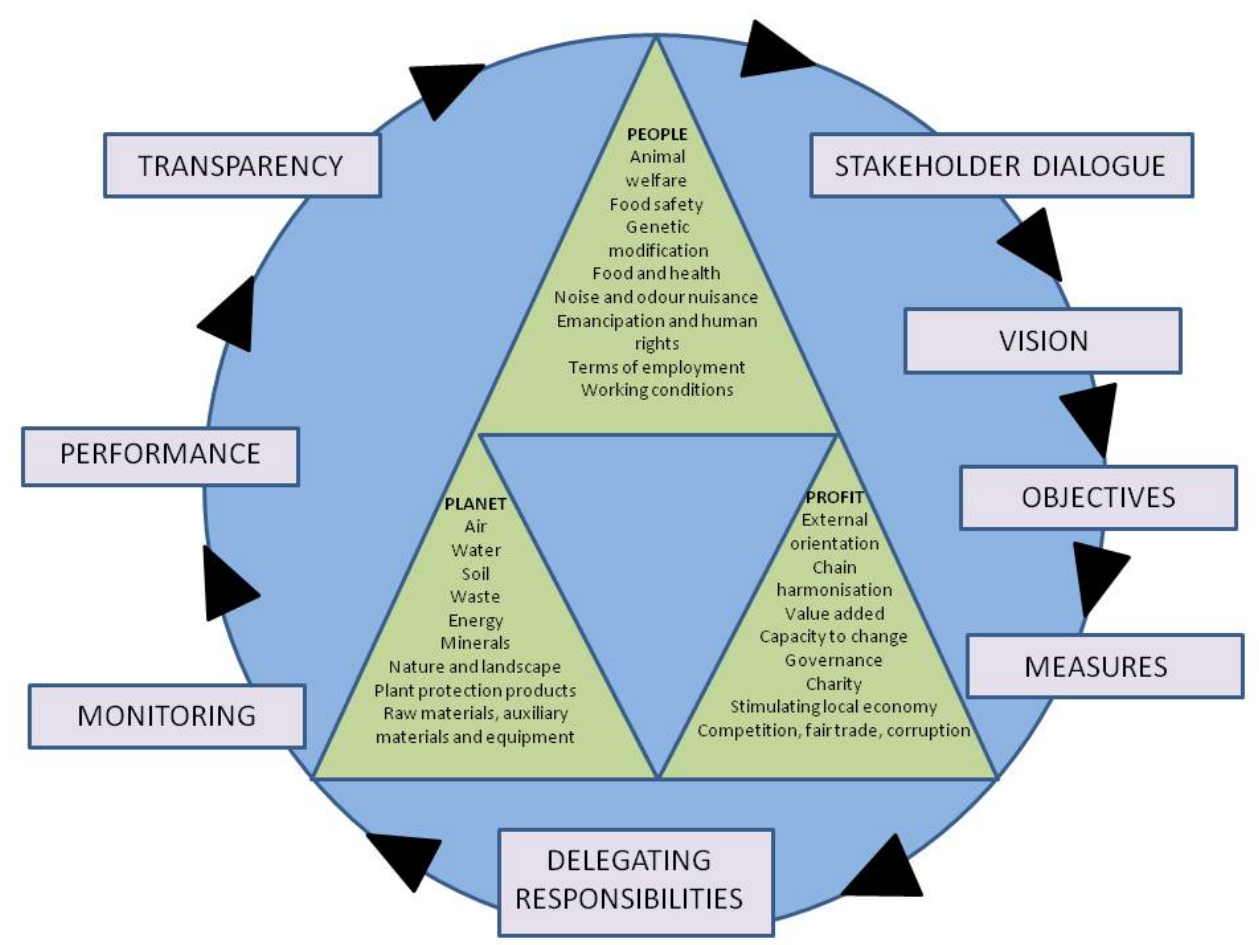

Fig. 1. Theoretical framework of the sustainability scan (Boone and ten Pierick, 2005).

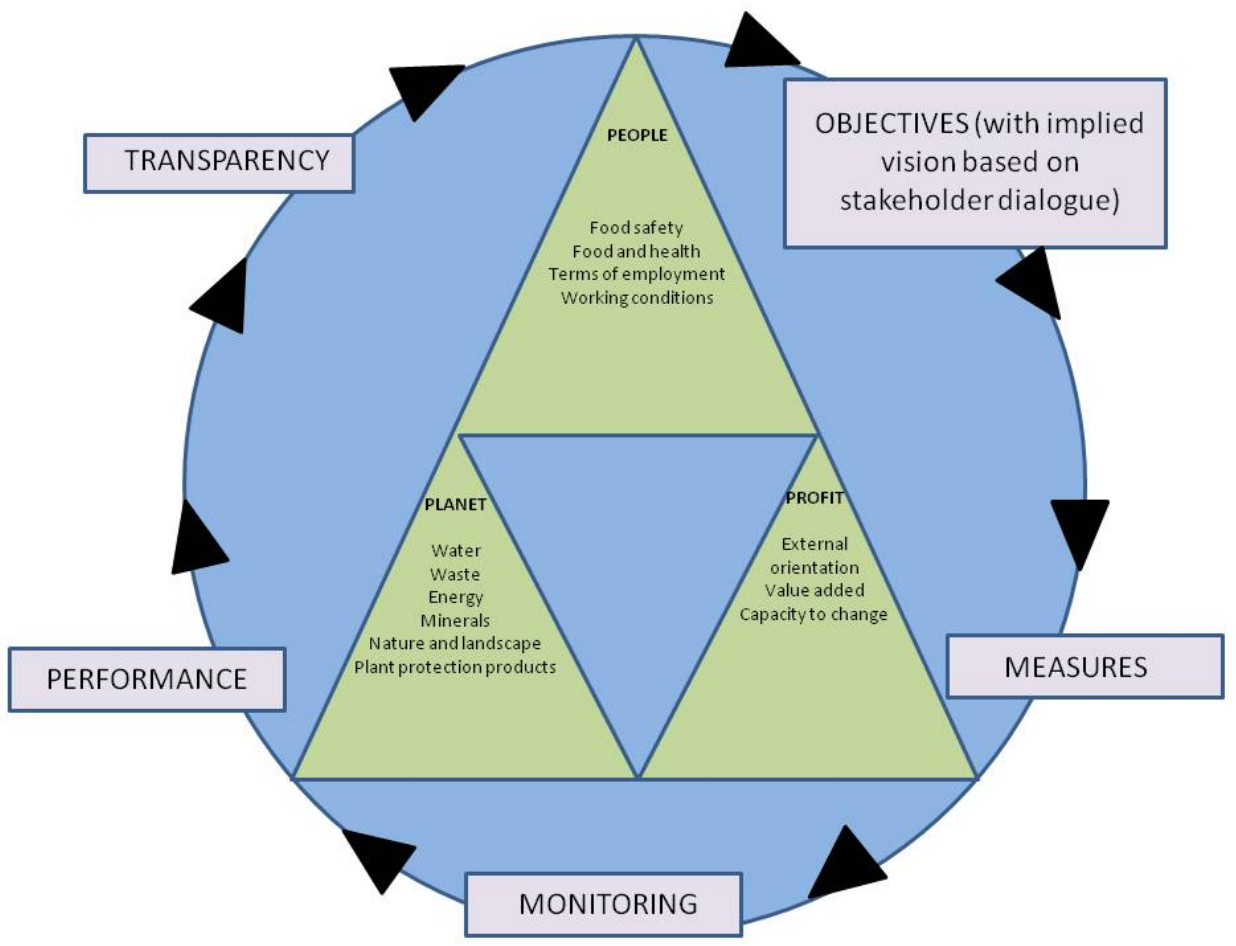

Fig. 2. Revised theoretical framework of the sustainability scan to the small business context of fruit production. 
